\title{
The Functional and Structural Neural Basis of Individual Differences in Loss Aversion
}

\author{
Nicola Canessa, ${ }^{1,2,3,4,5}$ Chiara Crespi, ${ }^{1,2}$ Matteo Motterlini, ${ }^{1,2,5}$ Gabriel Baud-Bovy, ${ }^{1,6}$ Gabriele Chierchia, ${ }^{1,2}$ \\ Giuseppe Pantaleo, ${ }^{1}$ Marco Tettamanti, ${ }^{2,7}$ and Stefano F. Cappa ${ }^{1,2,3,4,5}$ \\ ${ }^{1}$ Vita-Salute San Raffaele University, 20132 Milan, Italy, ${ }^{2}$ Center for Cognitive Neuroscience, Vita-Salute San Raffaele University, 20132 Milan, Italy, \\ ${ }^{3}$ Division of Neuroscience, San Raffaele Scientific Institute, 20132 Milan, Italy, ${ }^{4}$ CERMAC, San Raffaele Scientific Institute, 20132 Milan, Italy, ${ }^{5}$ CRESA, Vita- \\ Salute San Raffaele University, 20132 Milan, Italy, ${ }^{6}$ Robotics, Brain, and Cognitive Sciences Department, Istituto Italiano di Tecnologia, 16163 Genoa, Italy, \\ and ${ }^{7}$ Nuclear Medicine Department, San Raffaele Scientific Institute, 20132 Milan, Italy
}

Decision making under risk entails the anticipation of prospective outcomes, typically leading to the greater sensitivity to losses than gains known as loss aversion. Previous studies on the neural bases of choice-outcome anticipation and loss aversion provided inconsistent results, showing either bidirectional mesolimbic responses of activation for gains and deactivation for losses, or a specific amygdala involvement in processing losses. Here we focused on loss aversion with the aim to address interindividual differences in the neural bases of choice-outcome anticipation. Fifty-six healthy human participants accepted or rejected 104 mixed gambles offering equal (50\%) chances of gaining or losing different amounts of money while their brain activity was measured with functional magnetic resonance imaging (fMRI). We report both bidirectional and gain/loss-specific responses while evaluating risky gambles, with amygdala and posterior insula specifically tracking the magnitude of potential losses. At the individual level, loss aversion was reflected both in limbic fMRI responses and in gray matter volume in a structural amygdala-thalamus-striatum network, in which the volume of the "output" centromedial amygdala nuclei mediating avoidance behavior was negatively correlated with monetary performance. We conclude that outcome anticipation and ensuing loss aversion involve multiple neural systems, showing functional and structural individual variability directly related to the actual financial outcomes of choices. By supporting the simultaneous involvement of both appetitive and aversive processing in economic decision making, these results contribute to the interpretation of existing inconsistencies on the neural bases of anticipating choice outcomes.

\section{Introduction}

While cognitive theories (Kahneman and Tversky, 1979) and neuroscientific investigations (Rangel et al., 2008) ground decision making in the anticipation and evaluation of prospective gains and losses, a consistent view of the neural system(s) underpinning these processes is still missing.

Neurophysiological investigations have associated both the anticipation and the experience of rewards with the ventral striatum (VS) (Tobler et al., 2005). However, human neuroimaging studies investigating decision utility, i.e., the "pure" anticipation of outcomes without the expectation of their immediate experience, obtained inconsistent evidence. Anticipating rewards en-

Received Jan. 30, 2013; revised May 4, 2013; accepted June 17, 2013.

Author contributions: N.C., M.M., G.B.-B., and S.F.C. designed research; N.C., C.C., and G.C. performed research; M.M., G.P., and S.F.C. contributed unpublished reagents/analytic tools; N.C., C.C., G.B.-B., G.C., and M.T. analyzed data; N.C., C.C., G.B.-B., G.P., M.T., and S.F.C. wrote the paper.

C.C. was financially supported by the Cariplo Foundation Grant "Formazione Post-universitaria di Eccellenza in Medicina Molecolare." We acknowledge Schroders Italy SIM and the Cariplo Foundation Grant "Formazione Universitaria d'Eccellenza: applicazioni neuro-scientifiche per la formazione nella gestione dell'innovazione e della sostenibilità" for financial support. We thank Christian Bellebaum for his help in preparing the stimuli and for valuable comments on a first draft of this paper, as well as Dr. Silvia Caminiti and two anonymous reviewers for their insightful suggestions.

The authors declare no competing financial interests.

Correspondence should be addressed to Stefano F. Cappa, Vita-Salute San Raffaele University, via Olgettina 58, 20132 Milan, Italy.E-mail: cappa.stefano@hsr.it.

DOI:10.1523/JNEUROSCI.0497-13.2013

Copyright $\odot 2013$ the authors $\quad 0270-6474 / 13 / 3314307-11 \$ 15.00 / 0$ gages the VS (Knutson et al., 2001; Tobler et al., 2007), while anticipating negative outcomes was associated with amygdala activation in some studies (Yacubian et al., 2006; Canessa et al., 2009, 2011) but not in others (Tom et al., 2007; Smith et al., 2009). Recent data showed that loss anticipation involves the deactivation of mesocorticolimbic gain-related structures (i.e., bidirectional responses), with no activation specific to losses (Tom et al., 2007). In the same study, individual differences in loss aversion, i.e., the greater sensitivity to losses than equivalent gains (Kahneman and Tversky, 1984), was reflected in a steeper degree of deactivation versus activation in the VS, with no involvement of "emotional" regions such as insula and amygdala. The latter result, however, conflicts with the observation that amygdala damage eliminates loss aversion (De Martino et al., 2010), as well as with the reduction, induced by emotion regulation strategies, of both loss aversion and amygdala response to losses (Sokol-Hessner et al., 2013). Overall, the role of amygdala in loss anticipation highlighted by these data suggested that loss aversion may reflect a Pavlovian approach-avoidance response (De Martino et al., 2010), which involves the amygdala (Phelps and LeDoux, 2005), inhibiting action when outcomes are potentially aversive.

The inconsistencies between studies reporting or not reporting amygdala involvement may result from methodological factors, including the use of different tasks and stimuli (Yacubian et al., 2006; Tom et al., 2007), as well as ranges of potential gains/losses sampled from either symmetrical or asymmetrical payoff matrices (Tom et 
al., 2007 and De Martino et al., 2010). Moreover, some studies used subtractive (i.e., comparing "high" vs "low" gains/losses; Smith et al., 2009) rather than parametric (relating variable amounts of gain/loss with brain activity; Tom et al., 2007) designs, and most of them reported group data, thus neglecting the intrinsic individual variability when choosing. Finally, no studies investigated a neurostructural marker of loss aversion which, however, may provide critical cues about its neural basis.

Therefore, we focused on loss aversion to address interindividual differences in the neural bases of decision utility by coupling behavioral analyses with multimodal neuroimaging. We used functional magnetic resonance imaging (fMRI) to investigate whether individual differences in loss aversion were reflected in variations of brain activity underlying outcome anticipation, via bidirectional or gain/ loss specific responses, as well as multivariate source-based morphometry (SBM) to investigate a "loss-aversion structural network" and univariate voxel-based morphometry (VBM) to identify specific functional components within this network, and particularly its output regions linking choice behavior with financial performance.

\section{Materials and Methods}

Participants. Fifty-six healthy, right-handed (Oldfield, 1971) monolingual native speakers of Italian ( 29 females [mean age $=24.91, \mathrm{SD}=3.90$, range $=$ 19-33] and 27 males [mean age $=24.78, \mathrm{SD}=4.44$, range $=19-38$ ]) participated in the study. All subjects had normal or corrected-to-normal visual acuity. All reported no history of psychiatric or neurological disorders, nor of drug/substance use, and no current use of any psychoactive medications. To exclude cases of pathological gambling, they were screened with an Italian translation of the South Oaks Gambling Screen (Lesieur and Bloome, 1987). They gave their written informed consent to the experimental procedure, which was approved by the local Ethics Committee.

Task, stimuli, and procedure. Participants performed a gambling task entailing the anticipation of real monetary gains and losses. They were asked to accept or reject a series of 104 mixed gambles offering equal (fixed at 50\%) chances of gaining or losing different amounts of money (Fig. 1A). The possible gains and losses were sampled from a symmetrical matrix ranging from 1 and 99 a.u., and they were not significantly correlated with each other. Gambles were shown for $5 \mathrm{~s}$, and replaced by a fixation cross that prompted participants to indicate their choice with a response box. Interstimulus intervals (ISIs) between successive trials were presented in different ("jittered") durations across trials (Dale, 1999). The OptSeq2 Toolbox (http://surfer.nmr.mgh.harvard.edu/optseq/) was used to estimate the optimal ISIs (mean ISI $=5.96 \mathrm{~s}$, range $=2.5-18.75$ ). In line with standard procedures (Pantaleo, 2012), the 104 trials were assigned to four functional runs, whose order was individually randomized for each subject.

Participants' performance resulted either in the increase or decrease of an initial endowment that was delivered 1 week before scanning to minimize the perception of "windfall" gains. We focused on "decision utility," as gambles were not resolved immediately. Indeed, all the accepted gambles were covertly played by the computer, with all their outcomes contributing to the final monetary payoff. To encourage participants to reflect on the subjective attractiveness of each mixed gamble instead of relying on a fixed rule, we asked them to indicate one of three possible responses, namely "strongly accept," "weakly accept," and "reject." We used the software Presentation 11.0 (Neurobehavioral Systems http://www.neurobs.com) both for stimuli presentation and recording of subjects' answers.

Behavioral analysis. The probability of accepting the mixed gamble was modeled by a logistic psychometric function based on Prospect Theory (Kahneman and Tversky, 1979; Tversky and Kahneman, 1992) with separate linear utility functions for gains and losses (Tom et al., 2007):

$$
\begin{aligned}
\operatorname{Pr}\left(Y=1 \mid P_{G}, G, P_{L}, L\right)= & {\left[1+\exp \left(-\left\{U_{G}(G) P_{G}+U_{L}(L) P_{L}\right\}\right)\right]^{-1} } \\
& =\left[1+\exp \left(-\frac{(1-\lambda) G P_{G}+\lambda L P_{L}}{\beta}\right)\right]^{-1},
\end{aligned}
$$

where $U_{G}(G) P_{G}+U_{L}(L) P_{L}$ is the expected utility (EU) for a mixed gamble, and $U_{\mathrm{G}}(G)=\lambda_{G} G$ and $U_{L}(L)=\lambda_{L} L$ are the linear utility func- tions $\left(\lambda_{G}>0, \lambda_{L}>0, G>0\right.$ and $\left.L<0\right)$. As assumed by Prospect Theory, the utility functions depend on changes in wealth (gains and losses) rather than on the final state of wealth (Kahneman and Tversky, 1979; Tversky and Kahneman, 1992). Moreover, the model also assumes that gains and losses can be weighted differently. As in Tom et al. (2007), we did not include probability weighting functions and used linear utility functions to allow the comparison between the two studies. Given that this model does not relax the expectation principle by using probability weighting functions as in the case of Prospect Theory, we refer to it as the EU model. This model can be reparameterized in terms of weighted average between gains and losses where the weight for loss is $\lambda=\lambda_{L} /\left(\lambda_{L}+\right.$ $\left.\lambda_{G}\right)$ and a response uncertainty parameter $\beta=1 /\left(\lambda_{L}+\lambda_{G}\right)$. The weight $\lambda$ is closely related to the definition of loss aversion used by Tom et al. (2007) $\left(\lambda_{L} / \lambda_{G}=\lambda /(1-\lambda)\right)$. By definition, this parameter indicates a loss-averse subject when its value is larger than 0.5 . The response uncertainty parameter corresponds to the inverse of the slope of the psychometric function, and reflects how well EU separates the two possible responses.

The expected value (EV) model is as follows:

$$
\operatorname{Pr}\left(Y=1 \mid P_{G}, G, P_{L}, L\right)=\left[1+\exp \left(E V / \beta^{\prime}\right)\right]^{-1},
$$

where $E V=P_{G} G+P_{L} L$ is the EV, and is the average gain (or loss) that one would expect if the mixed gamble were repeated an infinite number of times. The expected value model is a special case of the EU model with $\lambda=0.5$ and $\beta^{\prime}=2 \beta$. Unlike the utility model, gains and losses have the same weight in the expected value model $\left(\lambda=0.5\right.$ implies that $\left.\lambda_{G}=\lambda_{L}\right)$. The statistical significance of the loss-aversion parameter can therefore be tested by means of a likelihood-ratio test where the difference between the residual variances of the two nested models follows a $\chi^{2}$ distribution with one degree of freedom. An individual maximizing her/his profit would accept the mixed gamble each time EV $>0$. Such an individual would be loss-neutral $(\lambda \approx 0.5)$ and have response uncertainty near zero $(\beta \approx 0)$.

To estimate participants' risk aversion, the EV model was extended to include the risk as follows:

$$
\operatorname{Pr}\left(Y=1 \mid P_{G}, G, P_{L}, L\right)=\left[1+\exp \left(\beta_{0}+\beta_{E V} E V+\beta_{R} R\right)\right]^{-1},
$$

where the risk $R=\left(G^{2} P_{G}\left(1-P_{G}\right)+L^{2} P_{L}\left(1-P_{L}\right)\right)^{1 / 2}$ corresponds to the SD of the possible outcomes of the gamble. In this model, the indifference curve $E V=\gamma_{0}+\gamma_{R} R$ with $\gamma_{0}=-\beta_{0} / \beta_{\mathrm{EV}}$ and $\gamma_{R}=-\beta_{R} / \beta_{\mathrm{EV}}$ expresses a trade-off between the expected value $E V$ and the risk $R$ of the gambles toward which the participant has no preference (i.e., $\operatorname{Pr}(Y=$ $\left.\left.1 \mid P_{G}, G, P_{L}, L\right)=0.5\right)$. By definition, a positive slope $\gamma_{R}$ signals a riskaverse person who accepts more risky gambles only with a commensurate increase of their expected value.

MR data acquisition. We acquired anatomical T1-weighted and functional T2*-weighted MR images with a $3 \mathrm{~T}$ Philips Achieva scanner (Philips Medical Systems), using an 8-channels Sense head coil (sense reduction factor $=2$ ). Functional images were acquired using a $\mathrm{T}^{*}$ weighted gradient-echo, echo-planar pulse sequence (42 interleaved transverse slices covering the whole brain except for posterior occipital regions in some subjects, tilted $30^{\circ}$ downward with respect to the bicommissural line to reduce susceptibility artifacts in orbitofrontal regions, $\mathrm{TR}=2500 \mathrm{~ms}, \mathrm{TE}=30 \mathrm{~ms}$, flip-angle $=85^{\circ}, \mathrm{FOV}=240 \mathrm{~mm} \times 240 \mathrm{~mm}$, slice thickness $=3 \mathrm{~mm}$, interslice gap $=0.2 \mathrm{~mm}$, in-plane resolution $=$ $1.88 \mathrm{~mm} \times 1.88 \mathrm{~mm}$ ). Each scanning sequence comprised 142 sequential volumes. A high-resolution T1-weighted anatomical scan (150 slices, $\mathrm{TR}=600 \mathrm{~ms}, \mathrm{TE}=20 \mathrm{~ms}$, slice thickness $=1 \mathrm{~mm}$, in-plane resolution $=$ $1 \mathrm{~mm} \times 1 \mathrm{~mm}$ ) was also acquired for each subject.

$f M R I$ data preprocessing and statistical analyses. Image preprocessing and statistical analyses were performed using SPM8 (http://www.fil.ion. ucl.ac.uk/spm), implemented in MATLAB v7.4 (MathWorks) (Worsley and Friston, 1995). We discarded the first six volumes of each functional run to allow for T1-equilibration effects. All remaining 912 volumes from each subject were then spatially realigned to the first volume of the first scan and unwarped, spatially normalized, and resampled in $2 \times 2 \times$ $2 \mathrm{~mm}^{3}$ voxels, spatially smoothed with an $8 \mathrm{~mm}$ full-width half- 
maximum (FWHM) isotropic Gaussian kernel, and globally scaled to 100. The resulting time series across each voxel were high-pass filtered to $1 / 128 \mathrm{~Hz}$, and serial autocorrelations modeled as an AR(1) process.

We used parametric statistical analyses to highlight brain regions in which, during gamble evaluation, activity was positively or negatively linearly related with the magnitude of the potential gain or loss, while controlling for the effect of the EV of the gamble. Statistical maps were generated using a random-effect model, implemented in a two-level procedure. At the first level, we modeled trials as mini-epochs lasting $5 \mathrm{~s}$ in a design matrix including three additional regressors modeling a linear parametric modulation of the evaluation-related activity by the overall $\mathrm{EV}$ of the gamble, the magnitude of potential gain, and the magnitude of potential loss. The last two regressors thus highlighted voxels in which activity was significantly related with the magnitude of prospective gains or losses (uncorrelated with each other) after accounting for the effect of the EV of the gamble. An additional regressor modeled the subject's actual choice (accept/reject), to exclude its potential effect from functional results. Regressors modeling events were convolved with a canonical hemodynamic response function, and parameter estimates for all regressors were obtained at each voxel by maximum-likelihood estimation.

At the second level, the first-level contrast images entered a fullfactorial design with sphericity correction for repeated measures to identify voxels in which activity was specifically correlated with the amount of potential gains or losses. We performed this procedure separately for the regions showing either positive or negative correlations with the amount of gain/loss (i.e., activations or deactivations). In all analyses, we thresholded the resulting statistical maps at $p<0.05$ corrected for multiple comparisons at the voxel level or based on cluster extent. We also assessed the hypothesis that the same regions that are activated by potential gains are also deactivated by potential losses, or vice versa (a "bidirectional response"). To this purpose, we used the conjunction-null test (Nichols et al., 2005) between the statistical maps of "activations for gains" and "deactivations for losses," as well as between "activations for losses" and "deactivations for gains."

We then focused on loss aversion to examine potential relationships between behavioral and neural individual differences. We regressed the statistical maps resulting from previous steps against the individual lossaversion parameter to assess whether bidirectional and gain/loss-specific anticipatory responses also reflected individual differences in behavioral loss aversion. To characterize the relationship between loss aversion and the positive versus negative components of the bidirectional responses (i.e., activations vs deactivations), we first correlated the individual lossaversion parameter with the strength of anticipatory neural activity (parameter estimates) of $4 \mathrm{~mm}$ radius spheres centered on their peak voxels, separately for activations (the positive component) and deactivations (the negative component). Then, we tested whether the correlation between loss aversion and neural activity was significantly different across activations and deactivations using a separate-slopes statistical model. Finally, we explicitly investigated a "neural loss-aversion" response in regions actively anticipating losses. Following Tom et al. (2007), for all subjects we subtracted the slope of the gain response from the slope of the loss response, and vice versa. The resulting single-subject images entered a multiple regression, to identify the voxels showing a significant positive correlation between behavioral and neural loss aversion, i.e., voxels in which greater behavioral sensitivity for losses than gains reflects stronger anticipatory neural activations for losses than gains, or for gains than losses. Finally, we examined the regions where stronger activity was associated with acceptance of the mixed gamble, compared with its rejection, after accounting for the effect of the amount of prospective outcomes.

The location of activation foci was determined in the stereotaxic space of Talairach and Tournoux (1988) after correcting for differences between the latter and the Montreal Neurological Institute (MNI) coordinate systems with a nonlinear transformation (http:// www.mrc-cbu.cam.ac.uk/Imaging/Common/mnispace.shtml).

$V B M$ preprocessing and statistical analyses. VBM preprocessing and statistical analyses were performed using SPM8 along with the VBM8 (http://dbm.neuro.uni-jena.de) and diffeomorphic anatomical registration through exponentiated lie algebra (DARTEL; Ashburner, 2007) toolboxes. VBM entailed five main steps: (1) bias correction of intensity nonuniformity, (2) spatial normalization of images to a standardized anatomical space, (3) extraction of the gray matter (GM) component from the normalized images, (4) smoothing ( $8 \mathrm{~mm}$ FWHM) of the GM images; and (5) statistical analysis of local differences in GM volume significantly related with loss aversion (Ashburner and Friston, 2000). To preserve actual GM values locally and perform volumetric analyses on "modulated" GM volumes, we multiplied the GM segments by the nonlinear components derived from the normalization matrix, to account for individual differences in brain orientation, alignment, and size globally.

GM maps were voxelwise correlated with the individual loss-aversion parameter using linear regression analyses. We first used whole-brain analyses and the cytoarchitectonic probabilistic mapping implemented in the SPM-Anatomy toolbox v1.8b (Eickhoff et al., 2005) to localize the regions showing significant effects. Then, based on a priori hypotheses (Ploghaus et al., 1999; De Martino et al., 2010; Sokol-Hessner et al., 2013), we focused on positive correlations between behavioral loss aversion and GM volume in the amygdala and posterior insula. These structures were anatomically defined by means of criteria independent from our fMRI, SBM, and VBM results. We first used whole-brain statistical parametric maps to apply a small-volume correction (SVC; Worsley et al., 1996) to the probabilistic cytoarchitectonic subdivisions of the human amygdala and posterior insula. Namely, we focused on the laterobasal (LB), superficial (SF), and centromedial (CM) amygdala nuclei groups (Amunts et al., 2005), as well as on dysgranular (LD1) and granular (LG1, LG2) insular areas (Kurth et al., 2010), in both hemispheres. In these maps, LB includes the lateral, basolateral, basomedial, and paralaminar nuclei; CM the central and medial nuclei; and SF the anterior amygdaloid area as well as the ventral and posterior cortical nuclei. Recent meta-analytic connectivity analyses confirmed the role of LB and $\mathrm{CM}$ nuclei groups in, respectively, coordinating high-level sensory input (cue learning) and mediating attentional, vegetative, and motor responses (fear expression) (Bzdok et al., 2012). As a complementary approach, for each subject we extracted the voxel values (first eigenvariate) of GM volume from the same 12 (six regions per hemisphere) cytoarchitectonic subdivisions. The resulting values were averaged within clusters and correlated with behavioral loss aversion using Pearson's $r$ coefficient and a statistical threshold of $p<0.004167$ (corresponding to $p<0.05$ corrected for multiple comparisons). Based on a priori hypotheses (Bzdok et al., 2012), in a separate analysis we assessed the presence of a positive correlation between GM volume in CM amygdala nuclei and monetary performance (i.e., overall payoff).

SBM preprocessing and statistical analysis. SBM employs spatial Independent Component Analysis (ICA) to decompose GM images into maximally independent spatial sources. It thus identifies independent patterns in GM images (i.e., "natural structural networks"; Xu et al., 2009), which then enter statistical analyses based on the expression of such patterns in individual subjects (i.e., a "loading coefficient"), to investigate group differences or correlations with variables of interest.

SBM entailed image preprocessing, ICA, and statistical analysis. The former step is identical to that performed for VBM. Therefore, we carried out spatial ICA on the same GM images that also entered VBM analyses, using the GIFT toolbox (http://icatb.sourceforge.net) (Calhoun et al., 2001). We performed ICA using a neural network algorithm (Infomax) that attempts to minimize the mutual information of the network outputs to identify naturally grouping and maximally independent sources (Bell and Sejnowski, 1995). ICA was repeated 250 times in Icasso (http://research.ics.aalto.fi/ica/icasso/) and resulting components were clustered to ensure the consistency and reliability of the results, which are quantified using a quality index $I_{q}$ ranging from 0 to 1 and reflecting the difference between intracluster and extracluster similarity (Himberg et al., 2004). We extracted 20 components from the GM images, all associated with an $I_{q}>0.8$ indicating a highly stable ICA decomposition (Allen et al., 2011). For all components we performed correlation analyses between individual loading coefficients and individual loss aversion, using Pearson's $r$ coefficient and a statistical threshold of $p<0.0025$ (corresponding to $p<0.05$ corrected for multiple comparisons). We obtained anatomical labels of clusters using the Anatomy-Toolbox v1.8b (Eickhoff et al., 2005). 

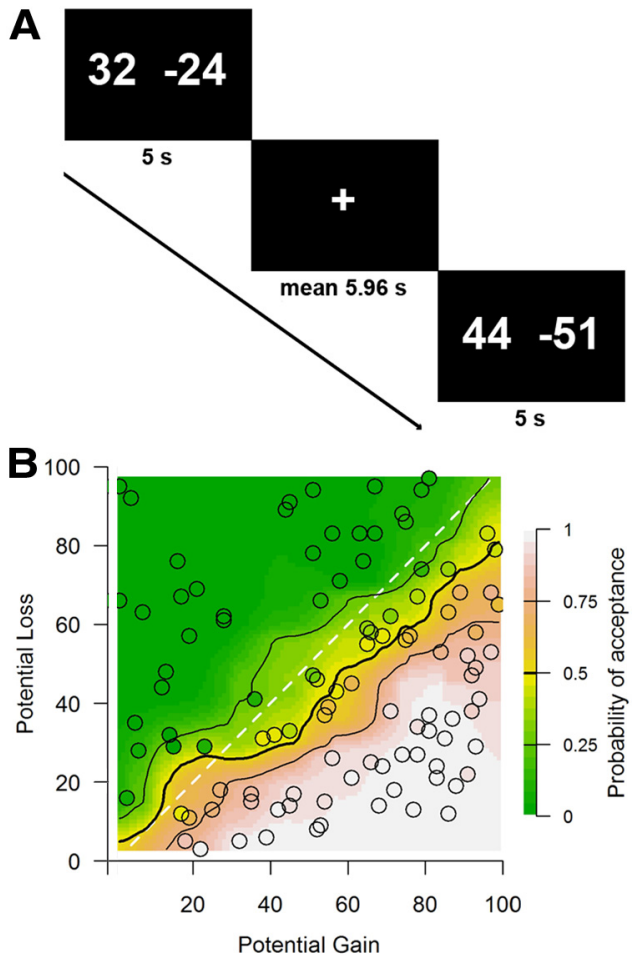

Figure 1. A, Gambling task. Participants were asked to accept or reject mixed gambles offering equal (50\%) chances of gaining or losing different amounts of money, with possible gains and losses sampled from a wide and symmetrical pay-off matrix (range: 1-99) and uncorrelated with each other. $\boldsymbol{B}$, Behavioral results. Color-coded heatmap depicting the probability of accepting the gamble (white, high; green, low) at different levels of gain/loss magnitude. The color within each circle codes the proportion of participants having accepted the gamble.

\section{Results}

\section{Behavioral results}

Two of 56 subjects were perfectly consistent with the EV model and did not exhibit any loss aversion. For the other subjects, the EU model fitted markedly better their responses than the EV model, indicating that they weighted gains and losses differently (Fig. $1 B$ ). In fact the percentage of correctly predicted responses for these 54 subjects increased from $82.1 \pm 10.6 \%$ for the EV model to $91.2 \pm 5.5 \%$ for the EU model (paired $t$ test, $t_{(53)}=7.06$, $p<0.001)$. The likelihood-ratio test between the two models was statistically significant ( $p<0.01$, see Materials and Methods) for $42(80.8 \%)$ of the subjects who were not perfectly consistent with the EV model. Among these subjects, $40(95.2 \%)$ were loss averse $(\lambda>0.5)$ and only $2(4.8 \%)$ were loss prone $(\lambda<0.5)$. These values fit with those reported in previous studies (Gachter et al., 2007). Loss aversion and response uncertainty were not correlated $(r=0.183, p=0.178)$. Two-sample $t$ tests highlighted no significant gender difference in overall payoff $\left(t_{(54)}=0.13, p=\right.$ $0.893)$, as well as a nonsignificant trend toward larger loss aversion $\left(t_{(54)}=1.78, p=0.079\right)$ and response uncertainty $\left(t_{(54)}=1.76, p=\right.$ $0.084)$ in females than males.

Loss aversion was significantly correlated with risk aversion $(r=0.70, p<0.0001)$. We thus ensured that the above results could not be interpreted in terms of risk aversion rather than loss aversion. First, the overall payoff was negatively correlated with loss aversion $(r=-0.32, p=0.016)$, but not with risk aversion $(r=-0.18, p=0.172)$. Indeed, a separate-slopes statistical model showed that payoff was more strongly related with loss aversion than with risk aversion $\left(F_{(2)}=3.982, p=0.021\right)$. Finally, partial correlations showed that the relationship between payoff and loss aversion remained significant even when controlling for risk aversion $(r=-0.27, p=0.043)$. In the converse analysis, controlling for loss aversion further reduced the correlation between payoff and risk aversion $(r=0.0602, p=0.662)$.

\section{fMRI results: neural loss aversion in bidirectional gain/loss responses}

Anticipating the magnitude of gains specifically increased brain activity in a right VS cluster involving the ventral caudate nucleus, putamen, and pallidum, as well as in bilateral orbitofrontal cortex (medial orbital sulcus on the boundary between medial and lateral orbitofrontal cortex), middle and superior frontal gyri, dorsal anterior cingulate cortex, posterior cingulate cortex, and portions of the dorsomedial thalamus projecting to temporal and prefrontal cortex (Fig. 2A, Table 1, Anticipation of gains).

Whole-brain conjunction-null (Nichols et al., 2005) analyses between "activation for gains" and "deactivation for losses" contrasts highlighted a bidirectional response in the left VS and in a posterior frontomedial cluster involving the dorsal anterior cingulate cortex and supplementary motor area (SMA; Fig. 2A, Table 1, Bidirectional response). Correlation analyses highlighted a significant relationship between individual loss aversion and strength of activity in both the frontomedial cortex (deactivation: $r=0.52, p<0.0001$; activation: $r=0.30, p=0.025)$ and the VS (deactivation: $r=0.38, p=0.0048$; activation: $r=0.27, p=$ 0.0436; Fig. $2 B, C$ ), with the slope of deactivation for increasing losses being significantly greater than the slope of activation for increasing gains (separate-slopes model; frontomedial cortex: $F_{(2)}=11.74, p<0.0001$; VS: $F_{(2)}=6.389, p=0.002$; Figure $2 B, C)$.

We also observed the opposite bidirectional pattern in the right posterior insula/parietal operculum (OP). Here, indeed, individual loss aversion correlated with activity in a cluster where a bidirectional response reflected activation for losses and deactivation for gains (Fig. 3A, Table 2, Bidirectional response). In this case, the slope of the activation for increasing losses was significantly greater than the slope of the deactivation for increasing gains (separate-slopes model: $F_{(2)}=7.532, p=$ 0.0008 ), and only the former was significantly related with behavioral loss aversion (activation: $r=0.43, p=0.0009$; deactivation: $r=0.25, p=0.0685$; Fig. $3 B, C$ ).

\section{fMRI results: neural loss aversion in loss-specific responses}

In addition, parametric analyses revealed the presence of a lossspecific pattern in brain regions displaying loss-related activations in the absence of gain-related deactivations. These analyses highlighted a widespread limbic and somatosensory network specifically tracking the magnitude of potential losses (Fig. 3A, Table 2, Anticipation of losses). Its limbic component involved the amygdala and putamen in the right hemisphere. The somatosensory component included the middle cingulate cortex, as well as the posterior insula and rolandic operculum bilaterally. The latter cluster partially overlaps with the right hemispheric one displaying the loss-oriented bidirectional response previously described, but, unlike that region, it mostly involved the posterior insula bilaterally.

As in the case of the mesocorticolimbic bidirectional response, also the regions specifically tracking anticipated losses actively displayed a neural loss-aversion response related with behavioral loss aversion. Following Tom et al. (2007), we first computed neural loss aversion at each voxel by subtracting the slope of the gain response from the slope of the loss response. The results 


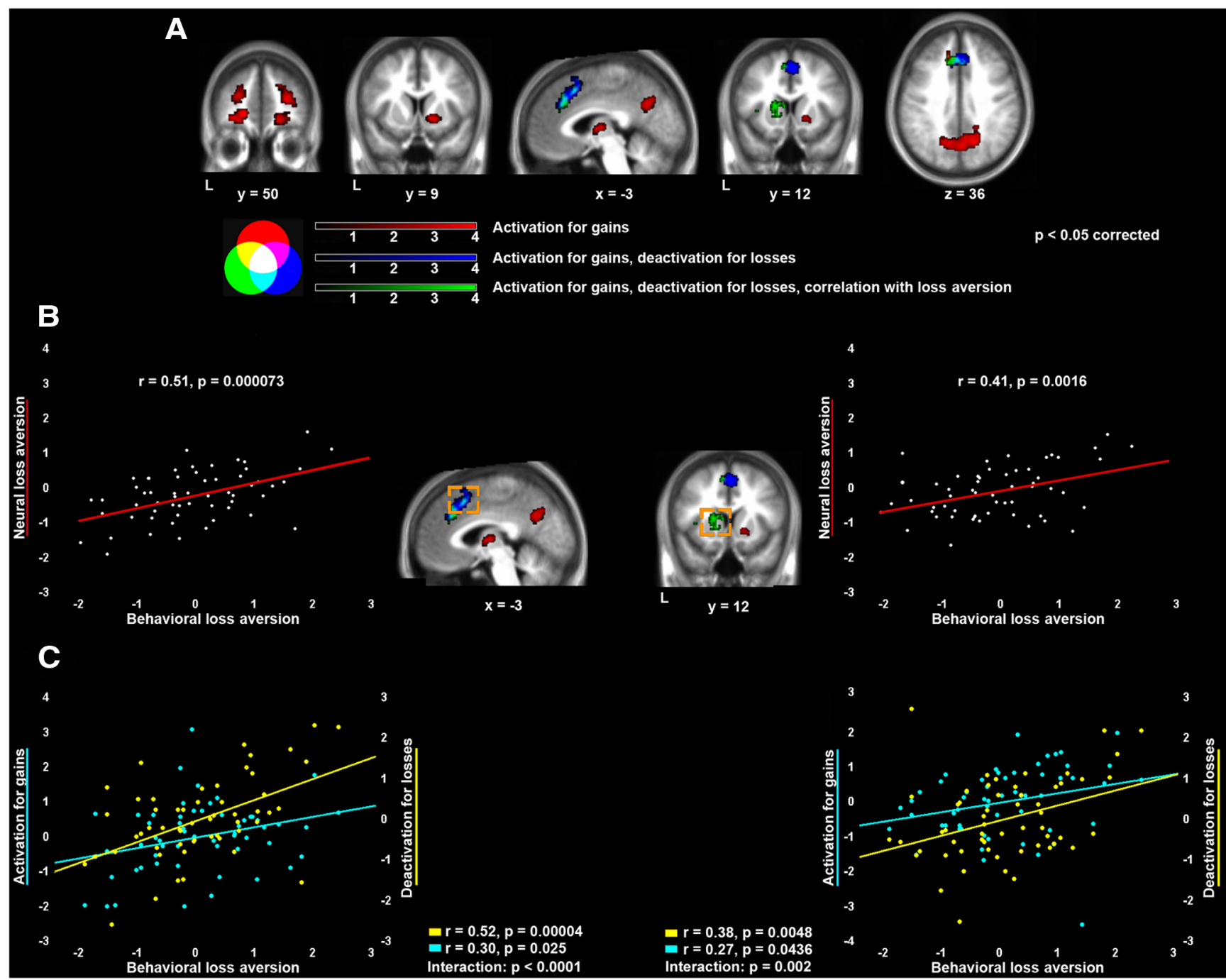

Figure 2. Neural anticipation of gains. $A$, The brain regions that were specifically activated by prospective gains (red), those displaying a bidirectional response (activation for gains, deactivation for losses; blue), and those displaying a bidirectional response tuned to behavioral loss aversion (green) ( $p<0.05$ corrected). $\boldsymbol{B}$, Scatterplots showing the significant correlation between behavioral loss aversion ( $x$-axis) and neural loss aversion $(y$-axis) in the posterior frontomedial cortex (left) and ventral striatum (right). $C$, Scatterplots showing the loss-aversion tuning of the negative component (deactivation for losses) of the bidirectional response in the same two regions (light-blue colors, activation for gains; yellow colors, deactivation for losses). Both parameter estimates of neural activity and behavioral loss aversion are represented as z-values in the scatterplots.

confirmed the somatosensory and limbic pattern of activity associated with the anticipation of losses per se (Table 3, Anticipation of losses vs gains). A whole-brain regression of behavioral loss aversion on neural loss aversion then confirmed the direct relationship between the two measures, involving most of the regions associated with loss anticipation per se, namely the right somatosensory cortex, posterior insula and rolandic operculum, middle cingulate cortex, and right amygdala (Fig. 4A, Table 3, Neural loss aversion: correlation between loss aversion and "losses minus gains"). We also investigated regions in which greater loss aversion was associated with stronger activity for the anticipation of gains, compared with losses. This analysis highlighted most of the structures associated with the anticipation of gains per se, namely dorsal anterior cingulate cortex extending into the SMA, left anterior insula, and striatum bilaterally (Fig. 4A, Table 3, Neural loss aversion: correlation between loss aversion and "gains minus losses”). The posterior frontomedial cluster including dorsal anterior cingulate cortex and SMA was also more strongly activated in association with gamble acceptance than rejection (Fig. 4B).

\section{A structural loss-aversion network highlighted by SBM} and VBM

Multivariate morphometric analyses provided evidence for a structural loss-aversion network. SBM employs spatial ICA to decompose GM images into maximally independent spatial sources without any a priori information. By taking into account the inter-relationship between all voxels, it thus identifies naturally grouped regions showing similar covariation between subjects (i.e., natural structural networks), as well as the differential expression of such patterns in individual subjects (a "loading coefficient" allowing to test group differences, or correlations with variables of interest). Individual loss aversion was significantly correlated $(r=0.46, p=0.000343)$ with only 1 of the 20 components estimated, involving bilaterally the amygdala (LB and SF nuclei), hippocampus [enthorinal cortex (EC) and cornu ammonis (CA)], putamen, ventral and dorsal striatum, and thalamus (Fig. 4C, Table 4, SBM results).

The mass-univariate approach of VBM highlighted more specific contributions of local variations of GM volume to individual 
Table 1. Neural anticipation of gains and bidirectional responses

\begin{tabular}{|c|c|c|c|c|c|c|c|}
\hline \multirow[b]{2}{*}{ Cluster size (number of voxels) } & \multirow[b]{2}{*}{ Hemisphere } & \multirow[b]{2}{*}{ Anatomical region } & \multicolumn{3}{|l|}{ MNI } & \multirow[b]{2}{*}{ Tscore } & \multirow[b]{2}{*}{ Cluster $p$ value } \\
\hline & & & $x$ & $y$ & $z$ & & \\
\hline \multicolumn{8}{|l|}{ Anticipation of gains } \\
\hline \multirow[t]{3}{*}{301} & $\mathrm{R}$ & Putamen & 18 & 8 & -6 & 3.75 & 0.02 \\
\hline & $\mathrm{R}$ & Caudate nucleus & 18 & 18 & 2 & 3.28 & \\
\hline & $\mathrm{R}$ & Pallidum & 22 & -6 & -6 & 4.93 & \\
\hline \multirow[t]{3}{*}{1204} & $\mathrm{~L}$ & Middle frontal gyrus & -28 & 36 & 18 & 4.16 & $<0.001$ \\
\hline & $\mathrm{L}$ & Superior frontal gyrus, orbital part & -18 & 54 & -4 & 3.76 & \\
\hline & $\mathrm{L}$ & Middle frontal gyrus, orbital part & -30 & 46 & -8 & 3.62 & \\
\hline \multirow[t]{2}{*}{362} & $\mathrm{R}$ & Superior frontal gyrus, orbital part & 18 & 52 & -12 & 4.61 & 0.01 \\
\hline & $\mathrm{R}$ & Middle frontal gyrus, orbital part & 30 & 44 & -10 & 3.01 & \\
\hline 434 & $\mathrm{R}$ & Superior frontal gyrus & 22 & 50 & 24 & 3.38 & 0.006 \\
\hline \multirow[t]{2}{*}{1026} & $\mathrm{~L}$ & Posterior cingulate cortex & -6 & -42 & 18 & 4.51 & $<0.001$ \\
\hline & $\mathrm{R}$ & Posterior cingulate cortex & 6 & -42 & 8 & 3.90 & \\
\hline \multirow[t]{2}{*}{1238} & $\mathrm{R}$ & Cuneus & 18 & -58 & 38 & 3.97 & $<0.001$ \\
\hline & $\mathrm{R}$ & Precuneus & 16 & -60 & 36 & 3.90 & \\
\hline \multirow[t]{2}{*}{404} & $\mathrm{R}$ & Thalamus (temporal) & 6 & -6 & 4 & 4.37 & 0.007 \\
\hline & $\mathrm{L}$ & Thalamus (prefrontal) & -12 & -10 & -2 & 3.44 & \\
\hline \multicolumn{8}{|c|}{$\begin{array}{l}\text { Bidirectional response: activation for gains, } \\
\text { deactivation for losses, correlation } \\
\text { with loss aversion }\end{array}$} \\
\hline \multirow[t]{6}{*}{265} & $\mathrm{~L}$ & Putamen/caudate nucleus* & -16 & 18 & -2 & 4.30 & $<0.001$ \\
\hline & $\mathrm{L}$ & Putamen & -18 & 10 & 4 & 4.05 & \\
\hline & $\mathrm{L}$ & Caudate nucleus & -14 & 14 & 10 & 4.01 & \\
\hline & $\mathrm{L}$ & Putamen & -24 & 8 & -4 & 4.00 & \\
\hline & $\mathrm{L}$ & Insula lobe & -28 & 20 & 6 & 3.79 & \\
\hline & $\mathrm{L}$ & Putamen & -22 & 18 & 0 & 3.59 & \\
\hline \multirow[t]{7}{*}{269} & $\mathrm{~L}$ & Middle cingulate cortex* & -4 & 28 & 32 & 4.44 & $<0.001$ \\
\hline & $\mathrm{L}$ & SMA & -4 & 16 & 46 & 4.09 & \\
\hline & $\mathrm{L}$ & Superior medial gyrus & -2 & 28 & 38 & 3.85 & \\
\hline & $\mathrm{R}$ & Superior medial gyrus & 10 & 24 & 42 & 3.82 & \\
\hline & $\mathrm{R}$ & Middle cingulate cortex & 4 & 26 & 32 & 3.66 & \\
\hline & $\mathrm{L}$ & Superior frontal gyrus & -12 & 28 & 38 & 3.57 & \\
\hline & $\mathrm{L}$ & Anterior cingulate cortex & -6 & 32 & 26 & 3.51 & \\
\hline
\end{tabular}

differences in loss aversion. Whole-brain analyses highlighted a significant positive correlation between behavioral loss aversion and GM volume in a left limbic cluster involving the CM, LB, and SF amygdala nuclei and the hippocampal cornu ammonis, as well as in the ventroposterior sector of the thalamus (Fig. 4C, Table 4; VBM results). To provide a detailed anatomical characterization of the role of amygdala and posterior insula in loss aversion, we performed a priori regions of interest analyses on their major cytoarchitectonic subdivisions. An SVC (Worsley et al., 1996) on the probabilistic cytoarchitectonic subdivisions of the human amygdala and posterior insula highlighted a significant positive correlation between behavioral loss aversion and GM volume in $\mathrm{LB}(p$ value $=0.00000097), \mathrm{CM}(p$ value $=0.000092)$, and SF $(p$ value $=0.000003$ ) left amygdala nuclei, as well as a trend in the right LG1 insular area ( $p$ value $=0.008$; compare with corrected $\alpha$-level $=0.004167)$. As a complementary approach, we correlated behavioral loss aversion with the average GM volume in the same 12 (six regions per hemisphere) cytoarchitectonic subdivisions. The results confirmed a significant correlation between loss aversion and GM volume in the left $\mathrm{CM}(r=0.45, p$ value $=$ $0.0005)$ and SF $(r=0.42, p$ value $=0.0013)$ amygdala nuclei, as well as in the right granular LG1 insular area $(r=0.39, p$ value $=$ 0.0026). Based on these results, and on the role of CM nuclei groups in mediating the expression of fear (Bzdok et al., 2012), in a separate analysis we assessed the specific a priori hypothesis that GM volume in the left CM nuclei may be related with the behavioral financial consequences of loss aversion (i.e., overall payoff). The results confirmed a weak but significant negative correlation between the two measures $(r=-0.27, p$ value $=0.046)$.
In addition to the aforementioned behavioral data, several control analyses excluded an interpretation of these results in terms of risk aversion rather than loss aversion. First, separateslopes statistical models showed that loss aversion was more strongly related than risk aversion with all morphometric measures, e.g., with GM volume in CM amygdala nuclei $\left(F_{(2)}=8.016\right.$, $p=0.0005)$, in the granular LG1 insular area $\left(F_{(2)}=5.048, p=\right.$ 0.008 ), and in the loss-aversion structural network highlighted by $\operatorname{SBM}\left(F_{(2)}=10.442, p<0.0001\right)$. Second, partial correlations showed that in all these regions the relationship between loss aversion and GM volume remained significant even after controlling for risk aversion (CM amygdala nuclei: $r=0.31, p=0.020$; granular LG1 insular area: $r=0.29, p=0.030$; loss-aversion structural network: $r=0.28, p=0.036$ ). In the converse analysis, controlling for loss aversion resulted in no significant relationship between risk aversion and GM volume in CM amygdala nuclei $(r=0.05, p=$ $0.738)$, granular LG1 insular area $(r=-0.001, p=0.993)$ and lossaversion structural network $(r=0.11, p=0.422)$.

\section{Discussion}

Our results show that anticipating outcomes when making choices simultaneously engages multiple neural mechanisms, reflecting both appetitive and aversive drives, in which the higher neural responsiveness to prospective losses than gains reflects individual differences in loss aversion.

Consistently with previous studies (Tom et al., 2007; Plassmann et al., 2010; Chib et al., 2012), one such mechanism involves bidirectional responses of a single mesocorticolimbic network. Within this network, stimuli or actions acquire a moti- 


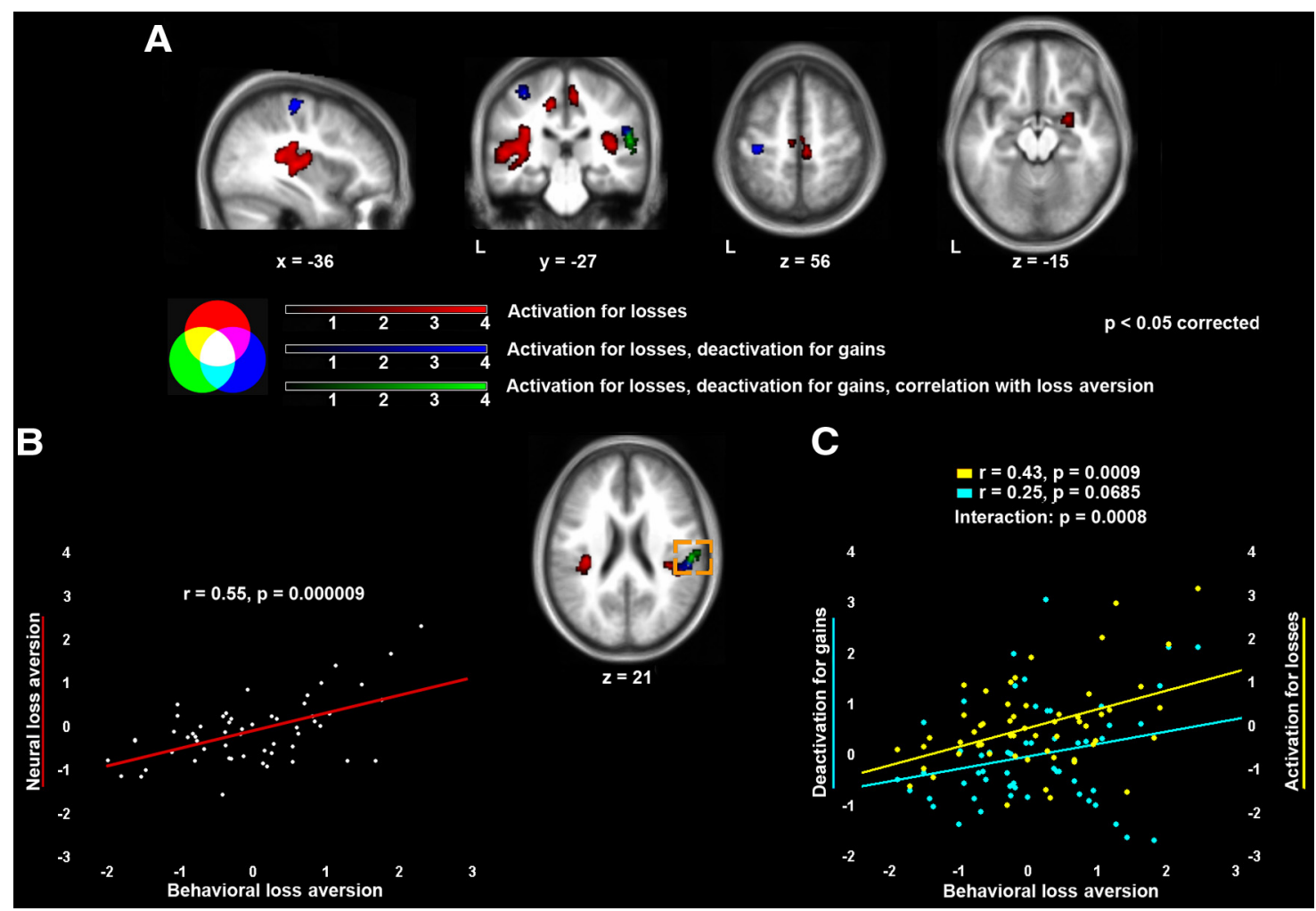

Figure 3. Neural anticipation of losses. $A$, The brain regions that were specifically activated by prospective losses (red), those displaying a bidirectional response (activation for losses, deactivation for gains; blue), and those displaying a bidirectional response tuned to behavioral loss aversion (green) ( $p<0.05$ corrected). $\boldsymbol{B}$, Scatterplots showing the significant correlation between behavioral loss aversion ( $x$-axis) and neural loss aversion (y-axis) in the right posterior insula and parietal operculum. C, Scatterplots showing the loss-aversion tuning of the positive component (activation for losses) of the bidirectional response in the same region (yellow colors, activation for losses; light-blue colors, deactivation for gains). Both parameter estimates of neural activity and behavioral loss aversion are represented as $z$-values in the scatterplots.

Table 2. Neural anticipation of losses and bidirectional responses

\begin{tabular}{|c|c|c|c|c|c|c|c|}
\hline \multirow[b]{2}{*}{ Cluster size (number of voxels) } & \multirow[b]{2}{*}{ Hemisphere } & \multirow[b]{2}{*}{ Anatomical region } & \multicolumn{3}{|l|}{ MNI } & \multirow[b]{2}{*}{ Tscore } & \multirow[b]{2}{*}{ Cluster $p$ valu } \\
\hline & & & $x$ & $y$ & $z$ & & \\
\hline \multicolumn{8}{|c|}{$\begin{array}{l}\text { Bidirectional response: activation for losses, deactivation } \\
\text { for gains, correlation with loss aversion }\end{array}$} \\
\hline \multirow[t]{2}{*}{175} & $\mathrm{R}$ & Rolandic operculum/Insula (OP1)* & 58 & -20 & 16 & 4.98 & \multirow[t]{2}{*}{$<0.001$} \\
\hline & $\mathrm{R}$ & Supramarginal gyrus (OP1) & 54 & -26 & 18 & 3.17 & \\
\hline \multicolumn{8}{|l|}{ Anticipation of losses } \\
\hline \multirow[t]{3}{*}{1019} & $\mathrm{~L}$ & Insula (LG1/LG2) & -38 & -22 & 8 & 4.52 & \multirow[t]{3}{*}{$<0.001$} \\
\hline & L & Insula lobe (OP3) & -36 & -14 & 10 & 3.83 & \\
\hline & L & Rolandic operculum (OP1/OP2) & -34 & -26 & 16 & 3.43 & \\
\hline \multirow[t]{3}{*}{893} & $\mathrm{R}$ & Superior temporal gyrus & 42 & -18 & 0 & 5.92 & \multirow[t]{3}{*}{$<0.001$} \\
\hline & $\mathrm{R}$ & Amygdala (CM/SF)/putamen & 28 & 2 & -10 & 5.15 & \\
\hline & $\mathrm{R}$ & Insula lobe ((LG1/LG2/OP1) & 36 & -28 & 18 & 3.37 & \\
\hline \multirow[t]{2}{*}{383} & $\mathrm{~L}$ & Middle cingulate cortex & -12 & -32 & 48 & 4.51 & \multirow[t]{2}{*}{0.032} \\
\hline & $\mathrm{R}$ & SMA & 8 & -28 & 54 & 3.43 & \\
\hline
\end{tabular}

Asterisk indicates the region whose bidirectional response is depicted in Figure 3.

vational significance for their potential "reward" value, which is anticipated when the same stimuli or actions are evaluated to make further choices (i.e., select actions) (Doya, 2008; Hare et al., 2010) (Fig. 2A, Table 1). Its key nodes in the left VS and posterior frontomedial cortex displayed joint sensitivity to gains and losses, and particularly a neural loss-aversion response whereby larger loss-related deactivations, compared with gain-related activations, bias choices toward the avoidance of aversive outcomes (Fig. 2 B, C, Table 1, Bidirectional response). Additionally, an oppositely valenced bidirectional pattern involves the right posterior insula and parietal operculum (Fig. $3 A$, Table 2, bidirectional response), where the slope of the activation for increasing losses is greater than the slope of the deactivation for increasing gains, and only the former is significantly related with loss aversion (Fig. $3 B, C)$. Regardless of their positive/negative direction, such bidirectional responses thus appear to bias the evaluation of anticipated outcomes, through a preferential tuning to anticipated losses rather than gains that reflects the degree of individual loss aversion.

A second, "loss-specific" neural mechanism in which the anticipation of outcomes reflects individual differences in loss aversion involves the right amygdala and putamen, as well as specific portions of the right posterior insula. The latter regions, indeed, were activated by anticipated losses in the absence of gain-related 
Table 3. Neural loss aversion

\begin{tabular}{|c|c|c|c|c|c|c|c|}
\hline \multirow[b]{2}{*}{ Cluster size (number of voxels) } & \multirow[b]{2}{*}{ Hemisphere } & \multirow[b]{2}{*}{ Anatomical region } & \multicolumn{3}{|l|}{ MNI } & \multirow[b]{2}{*}{ Tscore } & \multirow[b]{2}{*}{ Cluster $p$ value } \\
\hline & & & $x$ & $y$ & $z$ & & \\
\hline \multicolumn{8}{|l|}{ Anticipation of losses versus gains } \\
\hline \multirow{4}{*}{2851} & L & Rolandic operculum (OP1/OP2) & -40 & -32 & 16 & 5.28 & \\
\hline & L & Insula (LG1/LG2) & -36 & -22 & 2 & 4.85 & \\
\hline & L & Angular gyrus & -44 & -72 & 34 & 3.40 & \\
\hline & L & Supramarginal gyrus & -42 & -36 & 24 & 3.20 & \\
\hline \multirow{3}{*}{2359} & $\mathrm{R}$ & Amygdala (CM/SF)/putamen & 28 & 0 & -8 & 4.19 & \\
\hline & $\mathrm{R}$ & Superior temporal gyrus & 54 & -26 & 12 & 4.14 & \\
\hline & $\mathrm{R}$ & Rolandic operculum (OP1/OP2) & 42 & -24 & 16 & 3.76 & \\
\hline \multirow[t]{2}{*}{683} & $\mathrm{~L}$ & Middle cingulate cortex & -12 & -32 & 48 & 4.72 & $<0.001$ \\
\hline & $\mathrm{R}$ & SMA & 4 & -16 & 60 & 3.09 & \\
\hline \multicolumn{8}{|c|}{$\begin{array}{l}\text { Neural loss aversion: correlation between loss } \\
\text { aversion and "losses minus gains" }\end{array}$} \\
\hline \multirow{4}{*}{2649} & $\mathrm{R}$ & Rolandic operculum (OP4) & 52 & 4 & 2 & 5.03 & \\
\hline & $\mathrm{R}$ & Supramarginal gyrus & 52 & -34 & 24 & 5.03 & \\
\hline & $\mathrm{R}$ & Amygdala (CM/SF) & 24 & -2 & -16 & 4.92 & \\
\hline & $\mathrm{R}$ & Insula lobe & 42 & -10 & -8 & 4.48 & \\
\hline \multirow[t]{2}{*}{483} & $\mathrm{R}$ & Middle cingulate cortex & 10 & -22 & 44 & 4.96 & 0.007 \\
\hline & L & Middle cingulate cortex & -6 & -12 & 42 & 4.02 & \\
\hline \multicolumn{8}{|c|}{$\begin{array}{l}\text { Neural loss aversion: correlation between loss } \\
\text { aversion and "gains minus losses" }\end{array}$} \\
\hline \multirow[t]{5}{*}{468} & L & Ventral caudate nucleus & -12 & 16 & 0 & 4.68 & $<0.001$ \\
\hline & $\mathrm{L}$ & Dorsal caudate nucleus & -10 & 6 & 12 & 4.80 & \\
\hline & $\mathrm{R}$ & Ventral caudate nucleus & 14 & 14 & 2 & 4.22 & \\
\hline & $\mathrm{R}$ & Dorsal caudate nucleus & 14 & 8 & 12 & 4.19 & \\
\hline & $\mathrm{R}$ & Pallidum & 18 & 4 & 6 & 3.85 & \\
\hline 139 & $\mathrm{R}$ & Thalamus (prefrontal) & 10 & -16 & 0 & 5.26 & 0.045 \\
\hline
\end{tabular}

deactivations (Fig. 3A, Table 2, Anticipation of losses), and displayed a neural loss-aversion response significantly related with individual loss aversion (Fig. 4A, Table 3, Anticipation of losses vs gains and Neural loss aversion: correlation between loss aversion and "losses minus gains"). These structures are critical in the detection of, as well as in the physiological and behavioral response to, aversive events and potential threats (Sehlmeyer et al., 2009; Schlund et al., 2010; LeDoux, 2012). In particular, the central and basal nuclei of amygdala mediate the output to other structures involved in the expression of fear and anxiety, and particularly avoidance behavior via the striatum (Darvas et al., 2011). Moreover, this process involves the cingulate cortex and posterior insula (Fiddick, 2011), i.e., the sensory component of the so-called pain-matrix, a brain "defensive" system signaling potential threats (Legrain et al., 2011). The posterior insula receives viscerosensory and nociceptive information about the physiological body state from the ventroposterior medial nucleus of the thalamus (Craig, 2002), and in turn modulates sympathetic arousal via descending projections to autonomic nuclei (Critchley et al., 2002). Indeed, an augmented anticipation of aversive bodily states in the insula (Ploghaus et al., 1999; Shi and Davis, 1999) has been associated with critical facets of loss aversion such as anxious affects and avoidance behavior (Camerer, 2005; Paulus and Stein, 2006).

Our fMRI results thus show a relationship among loss anticipation, behavioral loss aversion, and neural activity in somatosensory and limbic regions involved in detecting and avoiding aversive outcomes. Along with the observation that bilateral amygdala lesions result in the lack of loss aversion despite normal processing of EV and risk (De Martino et al., 2010), these results point to a role of amygdala in biasing the anticipation of outcomes toward their negative affective consequences, such as fear and anxiety, represented in posterior insula. Such an aversive signal of prospective loss may either be learned via fear conditioning, i.e., the process of acquisition, storage, and expression of fears mediated by the amygdala (Phelps and LeDoux 2005), or reflect unconditioned responses biasing actions that may entail an immediate threat. Distinguishing between these hypotheses will require paradigms explicitly addressing the effect of past experience of loss on subsequent behavioral adaptations (i.e., learning). While the origins of loss aversion thus remain an open issue, our results show the role of limbic and somatosensory structures in mediating a prospective aversive signal that biases decision making toward the avoidance of potential losses despite poten- 


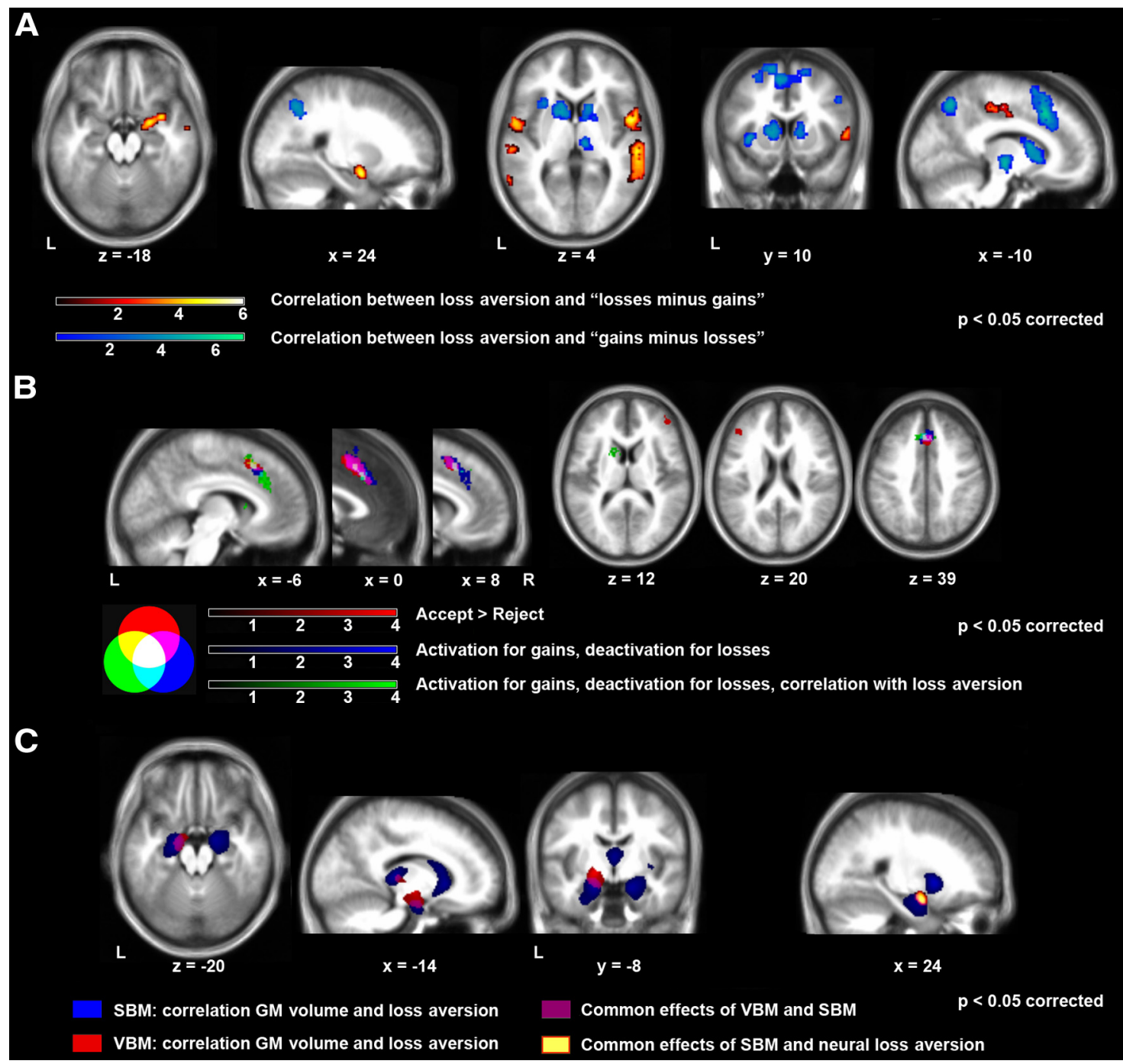

Figure 4. A, Neural loss aversion. The brain regions in which loss aversion was positively related with neural activity underlying the anticipation of losses (compared with gains; yellow) and gains (compared with losses; blue) ( $p<0.05$ corrected). $\boldsymbol{B}$, Acceptance versus rejection. The brain regions associated with acceptance, compared with rejection, of the mixed-gamble (while controlling for the anticipation of outcomes) are shown in red, along with those displaying a bidirectional response (activation for gains, deactivation for losses; blue) and those displaying a bidirectional response tuned to behavioral loss aversion (green) ( $p<0.05$ corrected). C, Neurostructural correlates of loss aversion. The loss-aversion structural network highlighted by SBM (blue), as well as the voxels where GM volume was positively related with loss aversion highlighted by VBM (red) ( $p<0.05$ corrected). Violet and yellow colors highlight the brain structures that were associated with loss aversion in both SBM and VBM analyses (left amygdala and thalamus; violet), as well as in both SBM and fMRI neural loss-aversion analyses (right amygdala; yellow).

Table 4. Neurostructural correlates of loss aversion

\begin{tabular}{|c|c|c|c|c|c|c|c|}
\hline \multirow[b]{2}{*}{ Cluster size (number of voxels) } & \multirow[b]{2}{*}{ Hemisphere } & \multirow[b]{2}{*}{ Anatomical region } & \multicolumn{3}{|l|}{ MNI } & \multirow[b]{2}{*}{ Tscore } & \multirow[b]{2}{*}{ Cluster $p$ value } \\
\hline & & & $x$ & $y$ & Z & & \\
\hline \multicolumn{8}{|c|}{ SBM results: a "loss-aversion structural network" } \\
\hline 1876 & $\mathrm{~L}$ & Amygdala (LB/SF)/hippocampus (EC/CA) & -18 & -7 & -21 & 6.31 & $<0.001$ \\
\hline 1512 & $\mathrm{R}$ & Amygdala (LB/SF)/hippocampus (EC/CA) & 18 & -6 & -23 & 6.39 & 0.0028 \\
\hline \multirow[t]{3}{*}{1274} & $\mathrm{~L}$ & Ventral caudate nucleus & -12 & 18 & 0 & 6.21 & 0.0066 \\
\hline & L & Dorsal caudate nucleus & -14 & 15 & 12 & 5.00 & \\
\hline & $\mathrm{L}$ & Putamen & -21 & 11 & -3 & 4.88 & \\
\hline \multirow[t]{3}{*}{1882} & $\mathrm{R}$ & Ventral caudate nucleus & 14 & 20 & -2 & 5.68 & $<0.001$ \\
\hline & $\mathrm{R}$ & Dorsal caudate nucleus & 15 & 14 & 15 & 5.45 & \\
\hline & $\mathrm{R}$ & Putamen & 24 & 11 & -2 & 7.94 & \\
\hline \multirow[t]{2}{*}{3112} & $\mathrm{~L}$ & Thalamus (prefrontal) & -9 & -25 & 7 & 8.60 & $<0.0001$ \\
\hline & $\mathrm{R}$ & Thalamus (temporal) & 2 & -15 & 6 & 10.89 & \\
\hline \multicolumn{8}{|c|}{$\begin{array}{l}\text { VBM results: voxelwise positive correlations between } \\
\text { GM volume and loss aversion }\end{array}$} \\
\hline 1051 & $\mathrm{~L}$ & Amygdala (CM/SF/LB) & -17 & -9 & -8 & 6.38 & 0.015 \\
\hline \multirow[t]{2}{*}{2203} & $\mathrm{~L}$ & Thalamus & -2 & -27 & 10 & 4.74 & 0.0001 \\
\hline & $\mathrm{R}$ & Thalamus & 3 & -27 & 7 & 4.78 & \\
\hline
\end{tabular}


tially equivalent gains. Moreover, by coupling behavioral analyses with morphometric techniques, we provide novel evidence on a neurostructural marker of loss aversion in amygdala nuclei and posterior insula.

Indeed, multivariate morphometric analyses revealed a structural loss-aversion bilateral network including amygdala, hippocampus, putamen, ventral and dorsal striatum, and thalamus (Fig. 4C, Table 4, SBM results). All these structures are key nodes of a network underpinning the detection of potential threats (Phelps and LeDoux, 2005; Sehlmeyer et al., 2009), although their specific role in generating a prospective loss signal is far from being clear. The striatum codes prediction errors, i.e., the difference between expected and actual outcomes, a critical learning signal in reinforcement-learning models (Schultz, 2007, 2013). Importantly, prediction errors code expectations about punishments in addition to rewards, that is an "aversive" prediction error (Seymour et al., 2007; Delgado et al., 2008) contributing to the anticipation of financial losses (Delgado et al., 2011). Moreover, in apparent contrast with its aforementioned role in detecting threats, the amygdala mediates avoidance learning also by predicting relief (Rogan et al., 2005; Seymour et al., 2005; Sangha et al., 2013). Therefore, further evidence is needed to unveil the precise role played in generating loss aversion by the structures encompassing the structural network highlighted by SBM. VBM analyses revealed more specific contributions to this process by a sector of the thalamus engaged by noxious stimulations (Paulson et al., 1998), and by right posterior insula and CM amygdala nuclei, likely reflecting the output of the anticipatory process and particularly the avoidance of those actions that may result in the negative affects associated with monetary losses (Fig. 4C, Table 4, VBM results). Individual differences in loss aversion and its behavioral financial consequences are thus specifically related to GM volume in amygdalar and para-amygdalar nuclei, and particularly CM nuclei mediating avoidance behavior. This result appears to ground loss aversion in a neural mechanism whereby individuals come to avoid actions that may entail aversive outcomes, whose sensory properties are represented in amygdala and posterior insula.

These neural structures likely compute a prospective loss signal that is integrated with other information, including gain-related signals, in downstream processing structures. It is likely that one such structure is the striatum, via well known connections with the amygdala (Amaral et al., 1992), where the integration of loss- and gain-related signals may generate the bidirectional response previously described. We observed the same bidirectional response in the posterior frontomedial cortex, which, alongside the striatum, has been associated with cost-benefit analyses (Croxson et al., 2009). The concurrent presence of gain and loss signals makes this region well suited for processing the trade-off between appetitive and aversive drives associated with a potential action. Interestingly, the posterior frontomedial cortex, alongside the lateral frontal cortex involved in cognitive control and action selection (Koechlin et al., 2003), was also more strongly activated by accepted, compared with rejected, gambles (Fig. 4B). This pattern of activity likely reflects the weighting of prospective gains and losses, overcoming the spontaneous tuning to losses and leading to gamble acceptance and superior decisional performance, when potential benefits are perceived as sufficiently higher than costs.

In conclusion, we contribute to the ongoing debate on the neural system(s) anticipating prospective choice outcomes (Tom et al., 2007; De Martino et al., 2010) by showing that multiple neural mechanisms are recruited while making choices, and that the biased anticipation of negative outcomes leading to loss aver- sion involves specific somatosensory and limbic structures. Importantly, despite a significant correlation between loss aversion and risk aversion, control analyses confirmed that both behavioral and neuroimaging findings reflect a disproportionate anticipation of losses, rather than risk. Our results support the view that the inconsistencies between previous neuroimaging (Tom et al., 2007) and lesional (De Martino et al., 2010) data on loss aversion may result from methodological issues. The authors of the latter study argued that, while their range of gains and losses was wide and symmetrical, in the Tom et al. (2007) study losses were short ranged and generally smaller than gains. The reduced range of potential losses, along with the overall positive expected value of the gambles, may have thus elicited only a weak and undetectable amygdala activity (De Martino et al. 2010). This interpretation is supported by the present study, in which gains and losses were sampled from a symmetrical and wide payoff matrix. Most importantly, we provide direct and novel morphometric evidence showing that a neurostructural signature of loss aversion can be found in a network involving amygdala, thalamus, striatum, and posterior insula. All these structures play a critical role in detecting threats and prepare the organism for appropriate action (LeDoux, 2012), with the connections between CM amygdala nuclei and the striatum mediating the avoidance of aversive events (Schlund et al., 2010). Our results, by showing a significant relationship among increased GM volume in CM amygdala nuclei, larger degree of loss aversion, and smaller monetary earnings, highlighted a direct link between individual differences in the structural properties of this network and the actual consequences of its associated behavioral defense responses in the financial domain.

\section{References}

Allen EA, Erhardt EB, Damaraju E, Gruner W, Segall JM, Silva RF, Havlicek M, Rachakonda S, Fries J, Kalyanam R, Michael AM, Caprihan A, Turner JA, Eichele T, Adelsheim S, Bryan AD, Bustillo J, Clark VP, Feldstein Ewing SW, Filbey F, et al. (2011) A baseline for the multivariate comparison of resting-state networks. Front Syst Neurosci 5:2. Medline

Amaral DG, Price JL, Pitkanen A, Carmichael ST (1992) Anatomical organization of the primate amygdaloid complex. In: The amygdala: neurobiological aspects of emotion, memory, and mental dysfunction (Aggleton JP, ed), pp 1-66. New York: Wiley.

Amunts K, Kedo O, Kindler M, Pieperhoff P, Mohlberg H, Shah NJ, Habel U, Schneider F, Zilles K (2005) Cytoarchitectonic mapping of the human amygdala, hippocampal region and entorhinal cortex: intersubject variability and probability maps. Anat Embryol 210:343-352. CrossRef Medline

Ashburner J (2007) A fast diffeomorphic image registration algorithm. Neuroimage 38:95-113. CrossRef Medline

Ashburner J, Friston KJ (2000) Voxel-based morphometry-the methods. Neuroimage 11:805-821. CrossRef Medline

Bell AJ, Sejnowski TJ (1995) An information-maximisation approach to blind separation and blind deconvolution. Neural Comput 7:1129-1159. CrossRef Medline

Bzdok D, Laird AR, Zilles K, Fox PT, Eickhoff SB (2012) An investigation of the structural, connectional, and functional subspecialization in the human amygdala. Hum Brain Mapp. Advance online publication. Retrieved July 17, 2012. doi:10.1002/hbm.22138. CrossRef Medline

Calhoun VD, Adali T, Pearlson GD, Pekar JJ (2001) A method for making group inferences from functional MRI data using independent component analysis. Hum Brain Mapp 14:140-151. CrossRef Medline

Camerer CF (2005) Three cheers-psychological, theoretical, empirical-for loss aversion. J Marketing Res 42:129-133. CrossRef

Canessa N, Motterlini M, Di Dio C, Perani D, Scifo P, Cappa SF, Rizzolatti G (2009) Understanding others' regret: a FMRI study. PLoS One 4:e7402. CrossRef Medline

Canessa N, Motterlini M, Alemanno F, Perani D, Cappa SF (2011) Learning from other people's experience: a neuroimaging study of decisional interactive-learning. Neuroimage 55:353-362. CrossRef Medline 
Chib VS, De Martino B, Shimojo S, O’Doherty JP (2012) Neural mechanisms underlying paradoxical performance for monetary incentives are driven by loss aversion. Neuron 74:582-594. CrossRef Medline

Craig AD (2002) How do you feel? Interoception: the sense of the physiological condition of the body. Nat Rev Neurosci 3:655-666. Medline

Critchley HD, Mathias CJ, Dolan RJ (2002) Fear conditioning in humans: the influence of awareness and autonomic arousal on functional neuroanatomy. Neuron 33:653-663. CrossRef Medline

Croxson PL, Walton ME, O’Reilly JX, Behrens TE, Rushworth MF (2009) Effort-based cost-benefit valuation and the human brain. J Neurosci 29: 4531-4541. CrossRef Medline

Dale AM (1999) Optimal experimental design for event-related fMRI. Hum Brain Mapp 8:109-114. CrossRef Medline

Darvas M, Fadok JP, Palmiter RD (2011) Requirement of dopamine signaling in the amygdala and striatum for learning and maintenance of a conditioned avoidance response. Learn Mem 18:136-143. CrossRef Medline

Delgado MR, Li J, Schiller D, Phelps EA (2008) The role of the striatum in aversive learning and aversive prediction errors. Philos Trans R Soc Lond B Biol Sci 363:3787-3800. CrossRef Medline

Delgado MR, Jou RL, Phelps EA (2011) Neural systems underlying aversive conditioning in humans with primary and secondary reinforcers. Front Neurosci 5:71. Medline

De Martino B, Camerer CF, Adolphs R (2010) Amygdala damage eliminates monetary loss aversion. Proc Natl Acad Sci U S A 107:3788-3792. CrossRef Medline

Doya K (2008) Modulators of decision making. Nat Neurosci 11:410-416. CrossRef Medline

Eickhoff SB, Stephan KE, Mohlberg H, Grefkes C, Fink GR, Amunts K, Zilles K (2005) A new SPM toolbox for combining probabilistic cytoarchitectonic maps and functional imaging data. Neuroimage 25:1325-1335. CrossRef Medline

Fiddick L (2011) There is more than the amygdala: potential threat assessment in the cingulate cortex. Neurosci Biobehav Rev 35:1007-1018. CrossRef Medline

Gachter S, Johnson EJ, Hermann A (2007) Individual-level loss aversion in riskless and risky choices. IZA Discussion Paper No 2961.

Hare TA, Camerer CF, Knoepfle DT, Rangel A (2010) Value computations in ventral medial prefrontal cortex during charitable decision making incorporate input from regions involved in social cognition. J Neurosci 30:583-590. CrossRef Medline

Himberg J, Hyvärinen A, Esposito F (2004) Validating the independent components of neuroimaging time series via clustering and visualization. Neuroimage 22:1214-1222. CrossRef Medline

Kahneman D, Tversky A (1979) Prospect theory: an analysis of decision under risk. Econometrica 47:263-292. CrossRef

Kahneman D, Tversky A (1984) Choices, values and frames. Am Psychologist 39:341-350. CrossRef

Knutson B, Adams CM, Fong GW, Hommer D (2001) Anticipation of increasing monetary reward selectively recruits nucleus accumbens. J Neurosci 21:RC159. Medline

Koechlin E, Ody C, Kouneiher F (2003) The architecture of cognitive control in the human prefrontal cortex. Science 302:1181-1185. CrossRef Medline

Kurth F, Eickhoff SB, Schleicher A, Hoemke L, Zilles K, Amunts K (2010) Cytoarchitecture and probabilistic maps of the human posterior insular cortex. Cereb Cortex 20:1448-1461. CrossRef Medline

LeDoux J (2012) Rethinking the emotional brain. Neuron 73:653-676. CrossRef Medline

Legrain V, Iannetti GD, Plaghki L, Mouraux A (2011) The pain matrix reloaded: a salience detection system for the body. Prog Neurobiol 93:111124. CrossRef Medline

Lesieur HR, Blume SB (1987) The South Oaks Gambling Screen (SOGS): a new instrument for the identification of pathological gamblers. Am J Psychiatry 144:1184-1188. Medline

Nichols T, Brett M, Andersson J, Wager T, Poline JB (2005) Valid conjunction inference with the minimum statistic. Neuroimage 25:653-660. CrossRef Medline

Oldfield RC (1971) The assessment and analysis of handedness: The Edinburgh inventory. Neuropsychologia 9:97-113. CrossRef Medline

Pantaleo G (2012) Guidelines for planning and conducting scientific research. Italian Oral Surgery 11:47-58. CrossRef
Paulson PE, Minoshima S, Morrow TJ, Casey KL (1998) Gender differences in pain perception and patterns of cerebral activation during noxious heat stimulation in humans. Pain 76:223-229. CrossRef Medline

Paulus MP, Stein MB (2006) An insular view of anxiety. Biol Psychiatry 60:383-387. CrossRef Medline

Phelps EA, LeDoux JE (2005) Contributions of the amygdala to emotion processing: from animal models to human behavior. Neuron 48:175-187. CrossRef Medline

Plassmann H, O'Doherty JP, Rangel A (2010) Appetitive and aversive goal values are encoded in the medial orbitofrontal cortex at the time of decision making. J Neurosci 30:10799-10808. CrossRef Medline

Ploghaus A, Tracey I, Gati JS, Clare S, Menon RS, Matthews PM, Rawlins JN (1999) Dissociating pain from its anticipation in the human brain. Science 284:1979-1981. CrossRef Medline

Rangel A, Camerer C, Montague PR (2008) A framework for studying the neurobiology of value-based decision making. Nat Rev Neurosci 9:545-556. CrossRef Medline

Rogan MT, Leon KS, Perez DL, Kandel ER (2005) Distinct neural signatures for safety and danger in the amygdala and striatum of the mouse. Neuron 46:309-320. CrossRef Medline

Sangha S, Chadick JZ, Janak PH (2013) Safety encoding in the Basal amygdala. J Neurosci 33:3744-3751. CrossRef Medline

Schlund MW, Siegle GJ, Ladouceur CD, Silk JS, Cataldo MF, Forbes EE, Dah RE, Ryan ND (2010) Nothing to fear? Neural systems supporting avoidance behavior in healthy youths. Neuroimage 52:710-719. CrossRef Medline

Schultz W (2007) Behavioral dopamine signals. Trends Neurosci 30:203-210. CrossRef Medline

Schultz W (2013) Updating dopamine reward signals. Curr Opin Neurobiol 23:229-238. CrossRef Medline

Sehlmeyer C, Schöning S, Zwitserlood P, Pfleiderer B, Kircher T, Arolt V, Konrad C (2009) Human fear conditioning and extinction in neuroimaging: a systematic review. PLoS One 4:e5865. CrossRef Medline

Seymour B, O'Doherty JP, Koltzenburg M, Wiech K, Frackowiak R, Friston K, Dolan R (2005) Opponent appetitive-aversive neural processes underlie predictive learning of pain relief. Nat Neurosci 8:1234-1240. CrossRef Medline

Seymour B, Daw N, Dayan P, Singer T, Dolan R (2007) Differential encoding of losses and gains in the human striatum. J Neurosci 27:4826-4831. CrossRef Medline

Shi C, Davis M (1999) Pain pathways involved in fear conditioning measured with fear-potentiated startle: lesion studies. J Neurosci 19:420-430. Medline

Smith BW, Mitchell DG, Hardin MG, Jazbec S, Fridberg D, Blair RJ, Ernst M (2009) Neural substrates of reward magnitude, probability, and risk during a wheel of fortune decision-making task. Neuroimage 44:600-609. CrossRef Medline

Sokol-Hessner P, Camerer CF, Phelps EA (2013) Emotion regulation reduces loss aversion and decreases amygdala responses to losses. Soc Cogn Affect Neurosci 8:341-350. Medline

Talairach J, Tournoux P (1988) Co-planar stereotaxic atlas of the human brain: 3-dimensional proportional system-an approach to cerebral imaging. New York: Thieme Medical.

Tobler PN, Fiorillo CD, Schultz W (2005) Adaptive coding of reward value by dopamine neurons. Science 307:1642-1645. CrossRef Medline

Tobler PN, O’Doherty JP, Dolan RJ, Schultz W (2007) Reward value coding distinct from risk attitude-related uncertainty coding in human reward systems. J Neurophysiol 97:1621-1632. Medline

Tom SM, Fox CR, Trepel C, Poldrack RA (2007) The neural basis of loss aversion in decision-making under risk. Science 315:515-518. CrossRef Medline

Tversky A, Kahneman D (1992) Advances in prospect theory: cumulative representation of uncertainty. J Risk Uncertainty, 5:297-323. CrossRef

Worsley KJ, Friston KJ (1995) Analysis of fMRI time-series revisited-again. Neuroimage 2:173-181. CrossRef Medline

Worsley KJ, Marrett S, Neelin P, Vandal AC, Friston KJ, Evans AC (1996) A unified statistical approach for determining significant signals in images of cerebral activation. Hum Brain Mapp 4:58-73. CrossRef Medline

Xu L, Groth KM, Pearlson G, Schretlen DJ, Calhoun VD (2009) Sourcebased morphometry: the use of independent component analysis to identify gray matter differences with application to schizophrenia. Hum Brain Mapp 30:711-724. CrossRef Medline 
Yacubian J, Gläscher J, Schroeder K, Sommer T, Braus DF, Büchel C (2006) Dissociable systems for gain- and loss-related value predictions and errors of prediction in the human brain. J Neurosci 26:9530-9537. CrossRef Medline 